Check for updates

Cite this: RSC Adv., 2018, 8, 20341

Received 4th March 2018 Accepted 18th May 2018

DOI: $10.1039 / c 8 r a 01886 c$

rsc.li/rsc-advances

\section{Enhanced electrocatalytic hydrogen generation from water via cobalt-doped $\mathrm{Cu}_{2} \mathrm{ZnSnS}_{4}$ nanoparticles $\uparrow$}

\author{
Renuka V. Digraskar, (D) ${ }^{a}$ Vijay S. Sapner, ${ }^{a}$ Shankar S. Narwade, ${ }^{a}$ Shivsharan M. Mali, ${ }^{a}$ \\ Anil V. Ghule ${ }^{b}$ and Bhaskar R. Sathe iD *a
}

\begin{abstract}
Herein, we adopted a novel noble metal-free Co-doped CZTS-based electrocatalyst for the hydrogen evolution reaction (HER), which was fabricated using a facile, effective, and scalable strategy by employing a sonochemical method. The optimized Co-doped CZTS electrocatalyst shows a superior HER performance with a small overpotential of 200 and $298 \mathrm{mV}$ at 2 and $10 \mathrm{~mA}^{-1}$, respectively, and Tafel slope of $73 \mathrm{mV} \mathrm{dec}{ }^{-1}$, and also exhibits excellent stability up to 700 cycles with negligible loss of the cathodic current. The ease of synthesis and high activity of the Co-doped CZTS-based cost-effective catalytic system appear to be promising for HER catalysis.
\end{abstract}

\section{Introduction}

Intensification of the conflict caused by energy security with declining natural energy reserves and the increasing environmental problems together with the urge for the development of modern society have created a huge demand for futuristic renewable and environmentally friendly energy sources. Hydrogen $\left(\mathrm{H}_{2}\right)$, as an ideal clean energy carrier, is proposed to be a major energy resource for the future world. ${ }^{1}$ Currently, the traditional methods for the large-scale production of $\mathrm{H}_{2}$ involve the release of a large amount of $\mathrm{CO}_{2}$, high energy consumption and multistep and costly processes such as natural gas reforming and gasification of coal and petroleum coke. ${ }^{2}$ Thus, considerable efforts have been directed towards the sustainable production of $\mathrm{H}_{2}$ from water electrolysis as an emerging cleanenergy technology. ${ }^{3}$ Therefore, efficient cathode materials are needed to reduce the overpotential and improve the efficiency of the hydrogen evolution reaction (HER). Currently, expensive platinum (Pt) and Pt-based electrocatalysts are the most effective and electrochemically stable catalysts commonly used in the HER. ${ }^{4}$ Unfortunately, their scarcity and high cost limit their utilization on a large-scale for commercial applications. Thus, it is crucial and a key challenge to develop earth-abundant and inexpensive noble metal-free catalysts that possess good activity with high stability for the HER. Recently, many potential alternatives such as transition-metal dichalcogenides, ${ }^{5,6}$ carbides, ${ }^{7,8}$ phosphides, $^{\mathbf{9}}$ boride $^{\mathbf{1 0}}$ and nitrides ${ }^{\mathbf{1 1}}$ have been reported as

${ }^{a}$ Department of Chemistry, Dr Babasaheb Ambedkar Marathwada University, Aurangabad 431004, Maharashtra, India.E-mail: bhaskarsathe@gmail.com ${ }^{b}$ Department of Chemistry, Shivaji University, Kolhapur, Maharashtra, India $\dagger$ Electronic supplementary information (ESI) available. See DOI: $10.1039 / \mathrm{c} 8 \mathrm{ra01886c}$ efficient electrocatalysts for the HER. Among them, transitionmetal dichalcogenides (TMDs), i.e. $\mathrm{MoS}_{2}, \mathrm{CoS}_{2}$, and $\mathrm{WS}_{2}$, have attracted special attention due to their earth-abundant nature and promising properties as HER electrocatalysts. However, one of the challenges with layered dichalcogenide electrocatalysts is their poor electrical conductivity and small number of active sites, which are limited only to the edges, although some are reported to convert their thermodynamically favoured semiconducting phase to a metastable metallic polymorph., ${ }^{\mathbf{9 2 - 1 4}}$ Thus, Tan et al. reported the non-layered metal dichalcogenide $\mathrm{CoS}_{2}$ having an evident advantage over the layered metal dichalcogenides due to its conducting nature. ${ }^{9}$ In our previous work, we revealed that CZTS electrocatalysts show excellent HER activity, and thus more efforts have been made to further improve their HER activity. Interestingly, doping is one of the best strategies to further improve the catalytic performance. Several doped electrocatalysts have been reported, for instance, Liang et al. demonstrated an Fe-promoted MoP catalyst for enhanced HER performance compared to MoP. ${ }^{15}$ Liu et al. reported that an FeP/NCNT hybrid exhibited higher HER activity and stability than FeP NPs. ${ }^{16}$ Gao et al. reported N-doped $\mathrm{WS}_{2}$ nanosheets, which exhibit high electrocatalytic activity. ${ }^{17}$ Wang et al. demonstrated that an Ni-doped $\mathrm{MoS}_{2}$ catalyst shows excellent HER activity compared to pure $\mathrm{MoS}_{2} \cdot{ }^{18}$ More interestingly, the current research in this area is focused on using transition metals (Fe, Co, Ni, $\mathrm{Cu}, \mathrm{Cr}$, and $\mathrm{Zn}$ ) doped with boride, ${ }^{10}$ phosphide, ${ }^{19}$ carbide, ${ }^{20}$ and chalcogenide ( $\mathrm{S}$ and $\mathrm{Se}$ ), such as $\mathrm{MoS}_{2}, \mathrm{WS}_{2}$, and $\mathrm{FeS}_{2},{ }^{21-24}$ which have been found to be highly efficient catalysts for the HER. However, their preparation requires a gas chamber, costly and harmful chemicals, and very careful handling, thus prompting researchers to find cheaper alternatives. Nevertheless, to date, reports on the doping effect on the catalytic performance of Co-CZTS hydrogen 
evolution hybrid catalysts are rare. Based on the above research progress and corresponding HER studies, herein, we investigate improving the performance of the HER with the chalcogenide $\mathrm{Cu}_{2} \mathrm{ZnSnS}_{4}$ (CZTS) successfully doped with Co, which has a low cost, high earth abundance, small size, high current density and stability even in harsh acidic conditions and is promising for the HER by water splitting.

\section{Experimental section}

\subsection{Chemicals}

Copper chloride $\left(\mathrm{CuCl}_{2} \cdot 2 \mathrm{H}_{2} \mathrm{O}, 98 \%\right)$, zinc chloride $\left(\mathrm{ZnCl}_{2}\right.$ $\left.\cdot 2 \mathrm{H}_{2} \mathrm{O}, 96 \%\right)$, tin chloride $\left(\mathrm{SnCl}_{2} \cdot 2 \mathrm{H}_{2} \mathrm{O}, 98 \%\right)$, thioacetamide (TAA), cobalt chloride $\left(\mathrm{CoCl}_{2} \cdot 6 \mathrm{H}_{2} \mathrm{O}\right), 2$-methoxyethanol, monoethanolamine (MEA) and absolute ethanol of AR grade were used for the sonochemical synthesis of Co-doped CZTS nanoparticles. All the chemicals were procured from Sigma Aldrich and were used as received without any further purification.

\subsection{Synthesis of Co-doped CZTS nanoparticles}

Initially, the sol was prepared with the $\mathrm{Cu}: \mathrm{Zn}: \mathrm{Sn}:$ TAA ratio of $2: 1: 1: 4$ using the respective salt solutions. $1 \mathrm{M}$ of $\mathrm{CuCl}_{2}$ was dissolved in $100 \mathrm{~mL}$ of 2-methoxyethanol under vigorous stirring for $30 \mathrm{~min}$ followed by the addition of $0.5 \mathrm{M} \mathrm{ZnCl}_{2}$ and stirring for $15 \mathrm{~min}$. Then, $0.5 \mathrm{M} \mathrm{SnCl}_{4}$ was added with constant stirring for $15 \mathrm{~min}$ to obtain a clear solution. To this solution, 2 M TAA and an appropriate amount of monoethanolamine were added under continuous and vigorous stirring until the solution turned dark brown. Further, controlled doping was carried by the addition of $5 \mathrm{wt} \% \mathrm{CoCl}_{2}$ (doping amount) to this solution, which was then subjected to ultrasonication in an ultrasonic bath $(40 \mathrm{kHz}, 40 \mathrm{~W})$ for $1.5 \mathrm{~h}$ to achieve a black precipitate. The precipitate was repeatedly washed using absolute ethanol to remove excess TAA and other counter ions and then annealed at $170{ }^{\circ} \mathrm{C}$ (decomposition temperature of metalTAA complex) for $2 \mathrm{~h}^{.25}$ This as-synthesized Co-doped CZTS nanoparticles were further characterized and tested as an electrocatalyst for the HER. Interestingly, the electrocatalytic studies towards the water splitting reactions of the sonochemically synthesized CZTS nanoparticles are considered a point of interest in this work.

\subsection{Structural and morphological characterizations}

The product was analyzed via Fourier transform infrared spectroscopy (FTIR). Its phase and structure were characterized using X-ray diffraction (XRD, Siemens D-5005 diffractometer) equipped with an X-ray tube $(\mathrm{Cu} \mathrm{K} \alpha ; \lambda=1.5418 \mathrm{~nm}, 40 \mathrm{kV}, 30$ $\mathrm{mA}$, with a step size of $0.01^{\circ}$ ). X-ray photoelectron spectroscopy (XPS) on a SPECS HSA-3500 with a monochromatic $\mathrm{Al} \mathrm{K}_{\alpha} \mathrm{X}$-ray radiation X-ray source and hemispherical analyser was used to investigate the elemental states of the sample. The BET surface area of the CZTS powder-based catalyst was determined via $\mathrm{N}_{2}$ adsorption at $77 \mathrm{~K}$ and isotherm measurements at $77.3 \mathrm{~K}$ using a Quantachrome NovaWin@ 1994-2012, Quantachrome Instruments v11.02. Raman spectroscopy was performed using a Raman optical microscope, Seki Technotron Corp. Tokyo with a $532 \mathrm{~nm}$ laser. The electrochemical and electrocatalytic studies were performed using an electrochemical workstation (CHIInstrument 660E, USA) with a three-electrode system.

\subsection{Electrochemical measurements}

The electrochemical HER activity of the catalysts was tested by cyclic voltammetry (CV), linear sweep voltammetry (LSV) and electrochemical impedance spectroscopic (EIS) analysis. The measurements were performed on an electrochemical workstation (CHI-660E) using a three-electrode system with a modified glassy carbon electrode (GCE; $3 \mathrm{~mm}$ in dia.) as the working electrode, and saturated calomel electrode (SCE) and platinum wire as the reference and counter electrodes, respectively. Prior to use, the GCE was polished with $1 \mu \mathrm{m}, 0.3 \mu \mathrm{m}$ and $0.05 \mu \mathrm{m}$ alumina powder, respectively, followed by sonication in deionized water and methanol for 5 min each. For the fabrication of the working electrode, the catalyst ink was prepared by dispersing $5.0 \mathrm{mg}$ of catalyst into a mixed solvent containing 100 : 1 of isopropanol : Nafion ( $5 \mathrm{wt} \%$ ) solution and sonicating the mixture for $\sim 30 \mathrm{~min}$ to form a homogeneous ink. Afterwards, $10 \mu \mathrm{L}$ ( $0.41 \mathrm{mg}$ loading normalized to current density) of the catalytic ink was loaded onto the GCE and dried naturally at RT. Cyclic voltammetry (CV) and linear sweep voltammetry (LSV) were conducted in $0.5 \mathrm{M}$ aqueous $\mathrm{H}_{2} \mathrm{SO}_{4}$ electrolytic solutions. All the results are reported with respect to the reversible hydrogen electrode (RHE) in $0.5 \mathrm{M} \mathrm{H}_{2} \mathrm{SO}_{4}$, where $E$ $(\mathrm{RHE})=E(\mathrm{SCE})+0.244 \mathrm{~V}$. Electrochemical impedance spectroscopy (EIS) measurements were carried out from $1000000 \mathrm{~Hz}$ to $0.002 \mathrm{~Hz}$ at a slightly higher onset potential $(-0.21 \mathrm{~V} v s$. RHE).

\section{Results and discussion}

Scheme 1 shows a schematic of the synthesis of the Co-doped CZTS nanoparticles. FT-IR spectroscopy is usually employed to probe the various functional groups and inorganic and organic species and their inter- and intra-binding in samples. Thus, the

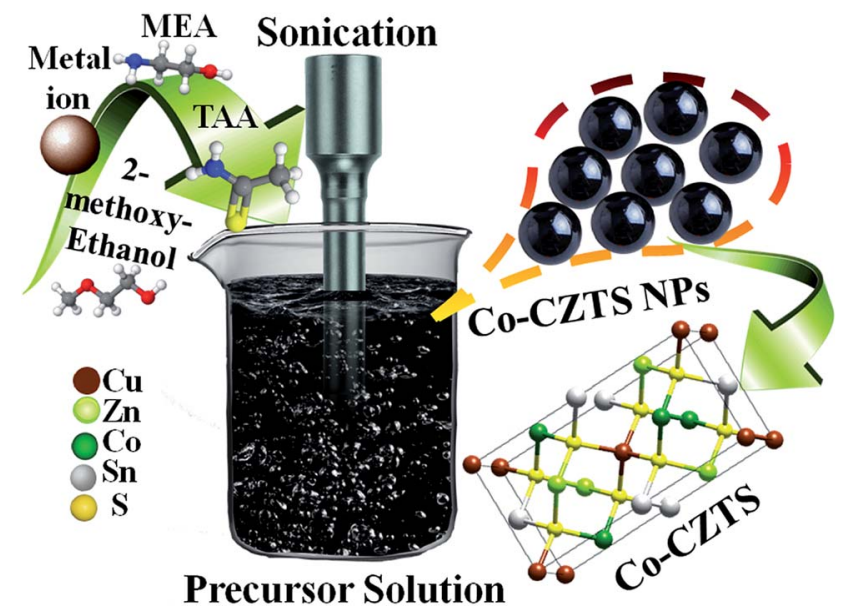

Scheme 1 Schematic illustration of the synthetic process for the Codoped CZTS NPs. 
undoped and Co-doped CZTS nanostructured samples were characterized via FT-IR spectroscopy for comparison in the spectral range of $400-4000 \mathrm{~cm}^{-1}$, as shown in Fig. 1(a). The spectra of the undoped and Co-doped CZTS samples show a common broad band at $3440 \mathrm{~cm}^{-1}$, which is attributed to the O-H stretching vibration, ${ }^{26}$ while the band at $1020 \mathrm{~cm}^{-1}$ corresponds to the $\mathrm{C}-\mathrm{S}$ stretching. The bands at 1430 and $1650 \mathrm{~cm}^{-1}$ are due to the coupled vibrations of the $\mathrm{C}-\mathrm{N}$ stretching and $\mathrm{N}-\mathrm{H}$ bending in the precursor complex, respectively. ${ }^{27}$ The band at $2360 \mathrm{~cm}^{-1}$ is attributed to the $\mathrm{S}-\mathrm{H}$ thiol functionality, which is in agreement with the literature value. ${ }^{28}$ Moreover, there are no obvious differences between the doped and undoped samples, suggesting that no new bonds are formed in the doped sample in the IR frequency range.

Fig. 1(b) shows the representative superimposed powder XRD patterns of the CZTS (I) and Co-doped CZTS (II) nanoparticles. The diffraction peaks in the spectra of both samples are indexed to the kesterite structure of CZTS, and the lattice parameters were calculated to $a=5.399 \AA$ and $c=10.873 \AA$ for pure CZTS and $a=5.396 \AA$ and $c=10.871 \AA$ for the Co-doped CZTS. These values are consistent with the literature values ( $a$ $=5.427 \AA$ and $c=10.848 \AA$, JCPDS no. 26-0575), thus the samples belong to the $142 \mathrm{~m}$ space group..$^{29,30}$ No extraneous peaks are observed, indicating the high purity of the final product. The average crystallite size obtained for the pure CZTS and Co-doped CZTS nanoparticles using the Scherrer equation is 4.0 and $3.2 \mathrm{~nm}$ and $\mathrm{W}-\mathrm{H}$ plot of 5.2 and $4.6 \mathrm{~nm}$, respectively. Significantly, upon doping with Co, a slight contraction in the lattice is observed, resulting in broadening of the diffraction peaks, which is in agreement with the literature. ${ }^{31}$ Moreover, the Raman and X-ray photoelectron spectroscopy (XPS) measurements give further evidence for the incorporation of Co into the CZTS lattice. Raman spectroscopy is a useful tool for the analysis of the effects of doping on nanomaterials because the incorporation of dopants leads to shifts in the lattice Raman vibrational peak positions. Accordingly, as shown in Fig. 1(c),

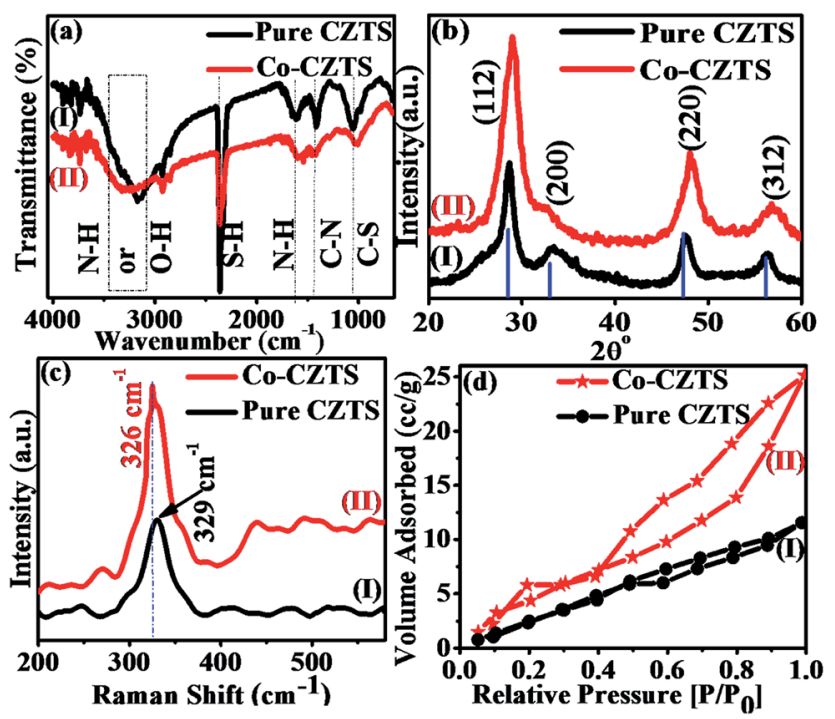

Fig. 1 Superimposed (a) FTIR, (b) XRD and (c) Raman spectra and (d) BET curves of CZTS (I) and Co-doped CZTS (II). the Raman spectra of the CZTS (I) and Co-doped (II) CZTS nanoparticles exhibit a strong peak located at $329 \mathrm{~cm}^{-1}$, which is indirect evidence of the formation of CZTS NPs. Moreover, after the doping of Co in CZTS, this peak shifts towards a lower energy of $326 \mathrm{~cm}^{-1}$, which can be attributed to electron molecular vibrational coupling due to the substitution of $\mathrm{Co}^{2+}$ ions in the host lattice or $\left(\mathrm{Zn}^{2+}\right.$ ions). ${ }^{32}$ Accordingly, the increased intensity of this mode for the cobalt-doped sample compared to the undoped sample suggests that the Co-doped sample contains a higher density of defects and lattice disorders, which is in agreement with literature. ${ }^{33}$ It is also important to note that there is no additional peak in the Raman spectra of the CZTS and Co-doped CZTS samples, which further confirms the absence of any spurious (and/or impurity) phases of dopant in the samples according to the literature survey. ${ }^{32}$ Fig. S1, ESI $\dagger$ presents the X-ray photoelectron spectra (XPS) of the samples, which further support our earlier findings of the incorporation of Co into the host lattice of the $\mathrm{Cu}_{2} \mathrm{ZnSnS}_{4}$ nanocrystals, where the cobalt atoms are $\mathrm{Co}^{2+}$ substituting the $\mathrm{Zn}^{2+}$ lattice sites in CZTS. The lower binding energy of the $2 \mathrm{p}^{3 / 2}$ peak at $778.1 \mathrm{eV}$ by $15.6 \mathrm{eV}$ is attributed to cobalt metal $\left(\mathrm{Co}^{0}\right),{ }^{34}$ and the detailed elucidation is presented in the ESI. $\dagger$ As shown in Fig. 1(d), the BET surface area of the Co-doped CZTS is $4.213 \mathrm{~m}^{2} \mathrm{~g}^{-1}$, which is slightly higher than the $2.016 \mathrm{~m}^{2} \mathrm{~g}^{-1}$ of CZTS due to the smaller particle size, pore-size distribution and pore volume of the undoped sample. The CZTS and Co-doped CZTS nanoparticles exhibited an average pore size of 3.578 and $4.617 \mathrm{~nm}$ and pore volume of 0.017 and $0.77 \mathrm{~cm}^{3} \mathrm{~g}^{-1}$, respectively. The higher surface area of the doped CZTS suggests it has enhanced electrocatalytic activity.

Fig. 2 shows the morphology of the CZTS nanoparticles before and after Co doping. Fig. 2(a) shows that the undoped CZTS nanoparticles are spherical with a uniform particle size distribution. The circled crystalline particles in Fig. 2(b) show the presence of several small-sized well dispersed CZTS NPs without any agglomeration with a slight difference in population. From the images it is clear that the morphology of CZTS did not change after Co doping. Moreover, (inset in Fig. 2(a) and (b)) the particle size distribution histograms of the pure and Codoped CZTS nanoparticles, respectively, demonstrate that their average particle size decreased because Co substituted $\mathrm{Zn}$ in the lattice sites, which creates defects. ${ }^{35}$ The particle size distribution was $2.6 \pm 0.4$ and $2.4 \pm 0.1$ for the pure CZTS and Co-doped CZTS, respectively, which is relatively lower than that reported for samples synthesized via other methods in the literature. ${ }^{36,37}$ Significantly, the reduction in particle size after Co doping in CZTS, where Co substituted $\mathrm{Zn}$ in the lattice sites, is attributed to the smaller ionic radius of $\mathrm{Co}^{2+}(0.72 \AA)$ than that of $\mathrm{Zn}^{2+}$ $(0.74 \AA)$, which is in good agreement with the XRD results. Consequently, the substitution of $\mathrm{Zn}$ by Co causes a decrease in the lattice constant. ${ }^{32}$ Accordingly, the fast-Fourier transform (FFT) pattern of the Co-doped CZTS nanoparticles in Fig. 2(c) corresponds to the diffraction spot reflecting the $d$-spacings of 3.1 and $2.7 \AA$, which can be indexed to the 112 and 200 planes, respectively. This is in agreement with the XRD analysis shown in Fig. 1(b). Moreover, lattice fringes with the $d$-spacing of 0.312 and $0.315 \mathrm{~nm}$ are also observed for the pure CZTS and Co-doped 

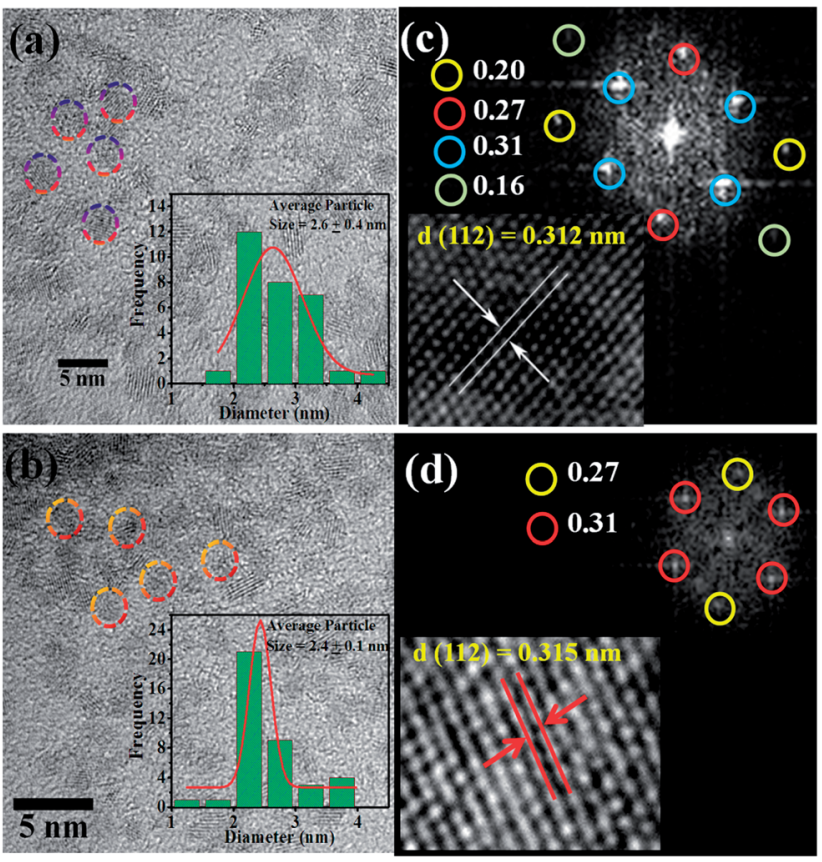

Fig. 2 HRTEM image of (a) pure CZTS NPs $(2.6 \pm 0.1 \mathrm{~nm})$ and (b) Codoped CZTS NPs $(2.4 \pm 0.1 \mathrm{~nm})$ (inset shows the particle size distribution plots). Fast-Fourier transform (FFT) patterns of (c) pure CZTS NPs and (d) Co-doped CZTS NPs (inset shows the lattice fringes).

CZTS, which correspond to the (112) representative plane of CZTS, as shown in Fig. 2(c) and (d), respectively.

\subsection{Electrochemical studies}

To demonstrate the enhancement in electrocatalytic activity CZTS after Co doping, cyclic voltammetry (CV) and linear sweep voltammetry (LSV) measurements were carried out and the results compared with that obtained for a Pt catalyst at a scan rate of $50 \mathrm{mV} \mathrm{s}^{-1} v s$. RHE in $0.5 \mathrm{M} \mathrm{H}_{2} \mathrm{SO}_{4}$ solution. As expected, Pt exhibited a much higher HER catalytic performance than the as-synthesised CZTS electrocatalysts. ${ }^{38}$ After doping Co (lowcost and earth-abundant element) in CZTS, its catalytic activity towards the HER was significantly promoted. Accordingly, Fig. 3(a) presents the superimposed LSV curves of the reference Pt, CZTS and Co-doped CZTS, which shows that the electrocatalytic performance of Co-CZTS is better than that of CZTS with an overpotential of 200 and $298 \mathrm{mV}$ at 2 and $10 \mathrm{~mA}^{-1}$, respectively, and it exhibits a higher current density of $-103 \mathrm{~mA}$ $\mathrm{cm}^{-1-2}$ (see Scheme S1 in ESI $\dagger$ ). A slight change in the features of the LSV curves at a scan rate from $10-100 \mathrm{mV} \mathrm{s}^{-1} v s$. RHE is observed, which reveals that the catalytic activity of the Codoped and undoped CZTS NPs toward the HER could be due to controlled mass transfer processes at the electrocatalytic interfaces (see S2 ESI $\dagger$ ). Table 1 shows a comparison of the HER performance of the catalysts in the present work with that of other electrocatalysts reported in the literature. From the table, we observe that the low overpotential and Tafel slope of CZTS indicate that it is a promising material for the HER. Since the Tafel slope represents the intrinsic activity of HER catalysts,
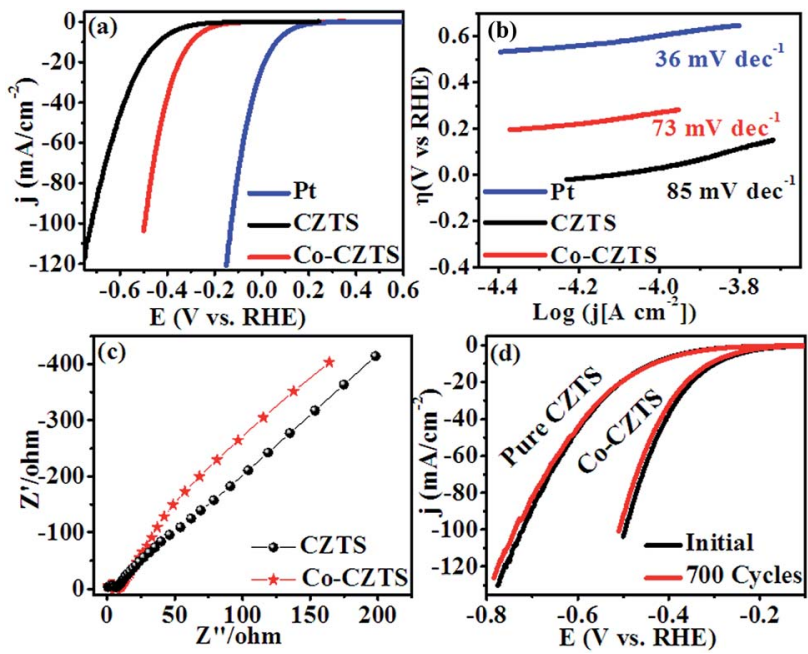

Fig. 3 (a) Polarization curves, (b) corresponding Tafel plots and (c) Nyquist plots of the CZTS and Co-doped CZTS NPs. (d) Durability test of Co-CZTS in $0.5 \mathrm{M} \mathrm{H}_{2} \mathrm{SO}_{4}$.

a smaller Tafel slope value represents a faster HER rate with respect to the increase in overpotential (positive shift). The Tafel slopes derived from the polarization curves were fitted into the Tafel equation $(\eta=a+b \log j$, where $b$ is the Tafel slope and $j$ is the current density). As shown in Fig. 3(b), the commercial Pt/C catalyst still shows the smallest Tafel slope of $\sim 36 \mathrm{mV} \mathrm{dec}^{-1}$, which is close to the reported values. ${ }^{39,40}$ Remarkably, the Codoped CZTS catalyst exhibits a smaller Tafel slope of $73 \mathrm{mV}$ $\operatorname{dec}^{-1}$ than that of the pure CZTS catalyst $\left(85 \mathrm{mV} \mathrm{dec}^{-1}\right)$, demonstrating its improved HER activity. ${ }^{41-43}$ Also, the exchange current density of the pure and Co-doped CZTS was 882 and $989 \mathrm{~mA} \mathrm{~cm}^{-2}$, respectively.

Table 1 Comparison of the electrocatalytic HER performance of nonnoble metal electrocatalysts with noble metal representative i.e. $\mathrm{Pd} / \mathrm{C}$ and Co-CZTS (this work) in $0.5 \mathrm{M} \mathrm{H}_{2} \mathrm{SO}_{4}$

\begin{tabular}{|c|c|c|c|c|}
\hline Sr. no. & Materials & $\begin{array}{l}\text { Overpotential } \\
\text { (mV vs. RHE) }\end{array}$ & $\begin{array}{l}\text { Tafel slope } \\
\left(\mathrm{mV} \mathrm{dec}^{-1}\right)\end{array}$ & Ref. \\
\hline 1 & $\mathrm{~F}-\mathrm{MoS}_{2}$ & 380 & 175 & 46 \\
\hline 2 & Co@C & 284 & 129.1 & 47 \\
\hline 3 & Bulk WS $W_{2}$ & 290 & 119 & 48 \\
\hline 4 & ZFO-700 & 377 & 178 & 49 \\
\hline 5 & $\mathrm{Pd} / \mathrm{C}$ & 264 & 124 & 50 \\
\hline 6 & MWCNTs@Cu & 366 & 109 & 51 \\
\hline 7 & $\mathrm{MoP}_{2} / \mathrm{Mo}$ & 273 & 69 & 52 \\
\hline 8 & CoTe NTs & 345.4 & 58.7 & 53 \\
\hline 9 & HCL-Ni@C & 440 & 194 & 54 \\
\hline 10 & $\mathrm{CoP}$ & 383 & 90 & 55 \\
\hline 11 & $\mathrm{Cu} / \mathrm{rGO}$ & -430 & 207 & 56 \\
\hline 12 & $\mathrm{MoS}_{2} \mathrm{NS}$ & 280 & 90 & 40 \\
\hline 13 & FeP NP & 292 & 86 & 16 \\
\hline 14 & $\mathrm{Ni}_{12} \mathrm{P}_{5}$ & 380 & 270 & 57 \\
\hline 15 & N,P-graphene-1 & 420 & 145 & 58 \\
\hline 16 & $\mathrm{Mo}_{2} \mathrm{C} @ N P C$ & 260 & 126.4 & 8 \\
\hline 17 & $\mathrm{Co}_{9} \mathrm{~S}_{8}$ & 224 & 135 & 59 \\
\hline 18 & Pristine $\mathrm{MoS}_{2}$ & 200 & 91 & 60 \\
\hline 19 & CZTS & 300 & 85 & 25 \\
\hline 20 & Co-CZTS & 200 & 73 & This \\
\hline
\end{tabular}


The significant enhancement in the final HER activity is mainly attributed to the synergistic effect of Co-doping in the CZTS NPs, which further enriched their defect structure and activated some unreactive edge sites. ${ }^{23}$ We further investigated the HER kinetics of the pure CZTS and Co-doped CZTS catalysts at the electrode/electrolyte interface via electrochemical impedance spectroscopy (EIS). The charge-transfer resistance $\left(R_{\mathrm{ct}}\right)$ is related to the electrocatalytic kinetics, where a lower value reflects a faster reaction rate, which can be obtained from the diameter of the semicircle in the EIS-Nyquist plot in the low frequency region. Accordingly, as shown in Fig. 3(c), the charge transfer resistance $\left(R_{\mathrm{ct}}\right)$ of CZTS $(6 \Omega)$ is higher than that of Co-CZTS $(4 \Omega)$, which indicates its poor conductivity. Thus, the doping of Co significantly improves the electron transport ability of CZTS during the HER process, suggesting that the incorporation of Co increases its electrical conductivity. ${ }^{23,44}$ Another important criterion for a good electrocatalyst is its current stability for a long period. To assess this, a continuous long-term operation of 700 HER cycles at a $50 \mathrm{mV} \mathrm{s}^{-1}$ scan rate was conducted in $0.5 \mathrm{M} \mathrm{H}_{2} \mathrm{SO}_{4}$ for the undoped and Co-doped CZTS catalyst. As shown in Fig. 3(d), a slight loss in activity was observed after 700 cycles, indicating the good durability of the catalysts in acidic media, which is consistent with that reported for CZTS-based systems. ${ }^{45}$ Furthermore, the turnover frequency (TOF) values were estimated for the HER in a $0.5 \mathrm{M} \mathrm{H}_{2} \mathrm{SO}_{4}$ solution using the method of Eric J. Popczun (see ESI $\dagger$ for detailed calculation) at $\eta=300 \mathrm{mV}$. The TOF of the Co-doped CZTS was calculated to be about $0.188 \mathrm{~s}^{-1}$, which is much larger than that of pure CZTS and indicates its superior intrinsic HER catalytic activity. Further, to highlight the significance of this report, our results were compared with that obtained in previous reports. The results demonstrate that the Co-doped CZTS electrode exhibits excellent electrocatalytic activity toward the HER (TOF comparison with other electrocatalysts see ESI Table S1†).

\section{Conclusion}

In summary, a facile sonochemical synthetic strategy has been developed to prepare Co-doped CZTS. XRD, Raman spectroscopy, HR-TEM and XPS were used to achieve a better understanding of the phenomena that occur when Co is incorporated into CZTS. The higher surface area of the Co-doped CZTS indicates its enhanced electrocatalytic activity. With the addition of Co, the HER activity of CZTS was greatly enhanced with a lower overpotential of $163 \mathrm{mV}$, smaller Tafel slope of $73 \mathrm{mV}$ $\operatorname{dec}^{-1}$, high stability even after 700 cycles and smaller charge transfer resistance. We believe that this work not only provides a low-cost and highly active HER system, but also open a new avenue for exploring the use of metal doping in chalcogenides as attractive catalyst materials for electrocatalytic applications in energy conversion devices.

\section{Conflicts of interest}

There are no conflicts to declare.

\section{Acknowledgements}

Author RVD is thankful to DAE-BRNS Mumbai for JRF fellowship. (F. No. 34/20/06/2014-BRNS/21gs), FAST-TRACK DSTSERB, New Delhi (SERB/F/7963/2014-15) and DST_SERB New Delhi research project No. (SERB/F/7490/2016-17) for financial support and Department of Chemistry, Dr Babasaheb Ambedkar Marathwada University, Aurangabad for laboratory facilities.

\section{Notes and references}

1 (a) M. Zeng and Y. Li, J. Mater. Chem. A, 2015, 3, 1494214962; (b) S. S. Narwade, B. B. Mulik, S. M. Mali and B. R. Sathe, Appl. Surf. Sci., 2017, 396, 939; (c) X. Zou, J. Su, R. Silva, A. Goswami, B. R. Sathe and T. Asefa, Angew. Chem., Int. Ed., 2014, 126, 4416; (d) B. R. Sathe, RSC Adv., 2013, 3, 5361-5365.

2 K. Christopher and R. Dimitrios, Energy Environ. Sci., 2012, 5, 6640-6651.

3 (a) Y. Zheng, Y. Jiao, Y. Zhu, L. H. Li, Y. Han, Y. Chen, A. Du, M. Jaroniec and S. Z. Qiao, Nat. Commun., 2014, 5, 3783; (b) B. R. Sathe, X. Zou and T. Asefa, Catal. Sci. Technol., 2014, 4, 2023; (c) B. R. Sathe, J. Electroanal. Chem., 2017, 799(15), 609616.

4 G.-R. Xu, J.-J. Hui, T. Huang, Y. Chen and J.-M. Lee, J. Power Sources, 2015, 285, 393-399.

5 Y. Wen, Y. D. Xia and S. W. Zhang, J. Power Sources, 2016, 307, 593-598.

6 L. Liao, J. Zhu, X. J. Bian, L. N. Zhu, M. D. Scanlon, H. H. Girault and B. H. Liu, Adv. Funct. Mater., 2013, 23, 5326-5333.

7 F. Harnisch, G. Sievers and U. Schroder, Appl. Catal., B, 2009, 89, 455-458.

8 J. S. Li, Y. Wang, C. H. Liu, S. L. Li, Y. G. Wang, L. Z. Dong, Z. H. Dai, Y. F. Li and Y. Q. Lan, Nat. Commun., 2016, 7, 11204.

9 Y. W. Tan, H. Wang, P. Liu, C. Cheng, F. Zhu, A. Hirata and M. W. Chen, Adv. Mater., 2016, 28, 2951-2955.

10 J. J. Borodzínski and A. Lasia, J. Appl. Electrochem., 1994, 24, 1267-1275.

11 T. Bhowmik, M. K. Kundu and S. Barman, ACS Catal., 2016, 6, 1929-1941.

12 M. S. Faber, R. Dziedzic, M. A. Lukowski, N. S. Kaiser, Q. Ding and S. Jin, J. Am. Chem. Soc., 2014, 136, 10053-10061.

13 C. H. Mu, H. X. Qi, Y. Q. Song, Z. P. Liu, L. X. Ji, J. G. Deng, Y. B. Liao and F. Scarpa, RSC Adv., 2016, 6, 23-30.

14 D. Voiry, M. Salehi, R. Silva, T. Fujita, M. Chen, T. Asefa, V. B. Shenoy, G. Eda and M. Chhowalla, Nano Lett., 2013, 13, 6222-6227.

15 X. Liang, D. Zhang, Z. Wu and D. Wang, Appl. Catal., A, 2016, 524, 134-138.

16 Q. Liu, Z. Pu, A. M. Asiri and X. Sun, Electrochim. Acta, 2014, 149, 324-329.

17 D. Gao, C. Sun, J. Zhang, J. Ma, P. Liu, K. Tao and D. Xue, J. Mater. Chem. A, 2016, 29, 11234-11238. 
18 D. Wang, X. Zhang, Y. Shen and Z. Wu, RSC Adv., 2016, 6, 16656-16661.

19 Y. Pan, Y. Liu, Y. Lin and C. Liu, ACS Appl. Mater. Interfaces, 2016, 8, 13890-13901.

20 H. Lin, N. Liu, Z. Shi, Y. Guo, Y. Tang and Q. Gao, Adv. Funct. Mater., 2016, 26, 5590-5598.

21 H. Wang, C. Tsai, D. Kong, K. Chan, F. Abild-Pedersen, J. Nørskov and Y. Cui, Nano Res., 2015, 8, 566-575.

22 D. Merki, H. Vrubel, L. Rovelli, S. Fierro and X. Hu, Chem. Sci., 2012, 3, 2515-2525.

23 H. Zhang, Y. Li, T. Xu, J. Wang, Z. Huo, P. Wan and X. Sun, J. Mater. Chem. A, 2015, 3, 15020-15023.

24 Y. Yang, X.-L. Fan, R. Pan and W.-J. Guo, Phys. Chem. Chem. Phys., 2016, 18, 10152-10157.

25 R. V. Digraskar, B. B. Mulik, P. S. Walke, A. V. Ghule and B. R. Sathe Appl, Surf. Sci., 2017, 412, 475-481.

26 J. Wang, P. Zhang, X. Song and L. Gao, RSC Adv., 2015, 5, 1220-1226.

27 T. K. Chaudhuri and D. Tiwari, Sol. Energy Mater. Sol. Cells, 2012, 101, 46-50.

28 M. Patel, I. Mukhopadhyay and A. Ray, J. Phys. D: Appl. Phys., 2012, 45, 445103.

29 K. Liu, B. Yao, Y. Li, Z. Ding, Z. Xiao, Y. Jiang, G. Wang and D. Pan, New J. Chem., 2017, 41, 685-691.

30 X. Zheng, J. Xu, K. Yan, H. Wang, Z. Wang and S. Yang, Chem. Mater., 2014, 26, 2344-2353.

31 P. Chetri, B. Saikia and A. Choudhury, J. Appl. Phys., 2013, 113, 233514.

32 (a) C. Xiao, K. Li, J. Zhang, W. Tong, Y. Liu, Z. Li, P. Huang, B. Pan, H. Su and Y. Xie, Mater. Horiz., 2014, 1, 81-86; (b) M. J. Thompson, K. J. Blakeney, S. D. Cady, M. D. Reichert, J. D. Pilar-Albaladejo, S. T. White and J. Vela, Chem. Mater., 2016, 28, 1668-1677.

33 J. Kegel, J. Halpin, F. Laffir, I. M. Povey and M. E. Pemble, CrystEngComm, 2017, 19, 1938-1946.

34 M. Ivill, S. J. Pearton, S. Rawal, L. Leu, P. Sadik, R. Das, A. F. Hebard, M. Chisholm, J. D. Budai and D. P. Norton, New J. Phys., 2008, 10, 065002.

35 J. K. Salem, T. M. Hammad, S. Kuhn, M. A. Draaz, N. K. Hejazy and R. Hempelmann, J. Mater. Sci.: Mater. Electron., 2014, 25, 2177-2182.

36 N. Jiang, L. Bogoev, M. Popova, S. Gul, J. Yano and Y. Sun, J. Mater. Chem. A, 2014, 2, 19407-19414.

37 B. Flynn, W. Wang, C. H. Chang and G. S. Herman, Phys. Status Solidi A, 2012, 209, 2186-2194.

38 K. L. Liu, F. M. Wang, K. Xu, T. A. Shifa, Z. Z. Cheng, X. Y. Zhan and J. He, Nanoscale, 2016, 8, 4699-4704.
39 Y. J. Bai, H. J. Zhang, X. Li, L. Liu, H. T. Xu, H. J. Qiu and Y. Wang, Nanoscale, 2015, 7, 1446-1453.

40 S. Muralikrishna, K. Manjunath, D. Samrat, V. Reddy, T. Ramakrishnappa and D. Nagaraju, RSC Adv., 2015, 5, 89389-89396.

41 D. Hou, W. Zhou, X. Liu, K. Zhou, J. Xie, G. Li and S. Chen, Electrochim. Acta, 2015, 166, 26-31.

42 D.-Y. Wang, M. Gong, H.-L. Chou, C.-J. Pan, H.-A. Chen, Y. Wu, M.-C. Lin, M. Guan, J. Yang and C.-W. Chen, J. Am. Chem. Soc., 2015, 137, 1587-1592.

43 Y. Li, H. Wang, L. Xie, Y. Liang, G. Hong and H. Dai, J. Am. Chem. Soc., 2011, 133, 7296-7299.

44 W. Fang, D. Liu, Q. Lu, X. Sun and A. M. Asiri, Electrochem. Commun., 2016, 63, 60-64.

45 P. Kush, K. Deori, A. Kumar and S. Deka, J. Mater. Chem. A, 2015, 3, 8098-8106.

46 B. J. Guo, K. Yu, H. L. Li, H. L. Song, Y. Y. Zhang, X. Lei, H. Fu, Y. H. Tan and Z. G. Zhu, ACS Appl. Mater. Interfaces, 2016, 8, 5517-5525.

47 H. B. Zhang, Z. J. Ma, J. J. Duan, H. M. Liu, G. G. Liu, T. Wang, K. Chang, M. Li, L. Shi, X. G. Meng, K. C. Wu and J. H. Ye, ACS Nano, 2016, 10, 684-694.

48 X. Zhao, X. Ma, J. Sun, D. H. Li and X. R. Yang, ACS Nano, 2016, 10, 2159-2166.

49 M. Y. Sun, Y. J. Chen, G. H. Tian, A. P. Wu, H. J. Yan and H. G. Fu, Electrochim. Acta, 2016, 190, 186-192.

50 K. Qi, S. S. Yu, Q. Y. Wang, W. Zhang, J. C. Fan, W. T. Zheng and X. Q. Cui, J. Mater. Chem. A, 2016, 4, 4025-4031.

51 F. Li, J. Li, X. Q. Lin, X. Z. Li, Y. Y. Fang, L. X. Jiao, X. C. An, Y. Fu, J. Jin and R. Li, J. Power Sources, 2015, 300, 301-308.

52 Z. H. Pu, I. S. Amiinu, M. Wang, Y. S. Yang and S. C. Mu, Nanoscale, 2016, 8, 8500-8504.

53 K. Wang, Z. G. Ye, C. Q. Liu, D. Xi, C. J. Zhou, Z. Q. Shi, H. Y. Xia, G. W. Liu and G. J. Qiao, ACS Appl. Mater. Interfaces, 2016, 8, 2910-2916.

54 L. Fan, P. F. Liu, X. Yan, L. Gu, Z. Z. Yang, H. G. Yang, S. Qiu and X. Yao, Nat. Commun., 2016, 7, 10667.

55 Y. Pan, Y. Lin, Y. Chen, Y. Liu and C. Liu, J. Mater. Chem. A, 2016, 4, 4745-4754.

56 F. Li, L. Zhang, J. Li, X. Lin, X. Li, Y. Fang, J. Huang, W. Li, M. Tian and J. Jin, J. Power Sources, 2015, 292, 15-22.

57 Y. Shi and B. Zhang, Chem. Soc. Rev., 2016, 45, 1529-1541.

58 Y. Zheng, Y. Jiao, L. H. Li, T. Xing, Y. Chen, M. Jaroniec and S. Z. Qiao, ACS Nano, 2014, 8, 5290-5296.

59 Y. Pan, Y. Q. Liu and C. G. Liu, Appl. Surf. Sci., 2015, 357, 1133-1140.

60 J. Guo, H. Zhu, Y. Sun, L. Tang and X. Zhang, Electrochim. Acta, 2016, 211, 603-610. 